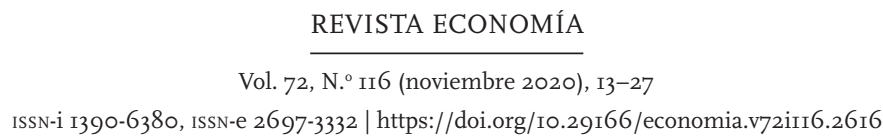

\title{
CIRCUITOS ECONÓMICOS DEL CAPITAL Y CIRCUITOS ECONÓMICOS SOLIDARIOS
}

\author{
CAPITAL ECONOMIC CIRCUITS AND SOLIDARITY ECONOMIC CIRCUITS
}

\author{
EUCLIDES A. MANCE \\ Universidad Federal ABC (Brasil) \\ Recepción del manuscrito: 27 de septiembre de 2020 \\ Aceptación versión final: 21 de noviembre de 2020
}

RESUMEN Este artículo presenta el concepto de circuito económico del capital, que remonta a Karl Marx, y de circuito económico solidario, que remonta a dos décadas de nuestra elaboración - siendo retomados aspectos de las publicaciones que realizamos entre 1999 y 2008, anteriores a publicación de Circuiti economici solidali [Roma: Pioda, 2017]—. El artículo analiza cómo el valor económico circula entre ambos circuitos, pudiendo ser determinado como valor-capital o como valor-solidario. Y presenta, en clave de economía de liberación, algunos elementos de la estrategia de organización de circuitos económicos solidarios para la liberación de fuerzas económicas y organización de sociedades poscapitalistas.

PALABRAS CLAVE Flujo económico, circuito económico, valor-capital, valor-solidario, liberación económica.

ABSTRACT This article presents the concept of the economy circuit of capital, which goes back to Karl Marx, and solidary economy circuit, which goes back two decades of our elaboration, taking up aspects of the publications we made between 1999 and 2008, prior to the publication of Circuiti economici solidali. It analyses how economy value circulates between the two circuits, which can be determined as capital-value or solidary-value. And it presents, in the key of the economy of liberation, some elements of the strategy of organization of solidary economy circuits for the liberation of economy forces and organization of post-capitalist societies.

KEYWORDS Economy flow, economy circuit, capital-value, solidary-value, economy liberation. JEL CODES P10, $\mathrm{P}_{49}, \mathrm{P}_{51}$.

\section{EL CONCEPTO DE CIRCUITO ECONÓMICO}

\subsection{CIRCUITO ECONÓMICO DEL CAPITAL}




\section{(a) Circulación y circuito económico}

Las ideas de circuito económico y de circulación del capital fueron largamente desarrolladas por Karl Marx. En algunas traducciones, Kapitalkreislauf aparece como circulación del capital o ciclo del capital; en otras como circuito del capital (Marx, 1956).

En el Libro 1 de El capital, Marx (1962) destaca la diferencia lógica de partir de la Mercancía o del Dinero en la comprensión de la circulación del valor:

El circuito M-D-M parte del extremo - una mercancía - y termina en el extremo - una otra mercancía-, que sale de la circulación y cae en el consumo. Consumo, satisfacción de necesidades, en una palabra, valor de uso es, pues, su fin último. El circuito D-M-D sale, por el contrario, del extremo - dinero- y regresa, por fin, al mismo extremo. Su motivo impulsor y fin determinante es, así, el propio valor de cambio. (p. 164)

\section{(b) Flujos económicos}

En los circuitos económicos del capital hay, necesariamente, flujos económicos en el proceso de circulación del valor.

Las diferentes determinaciones por que pasa el capital en su metamorfosis están asociadas al flujo del valor en su proceso como un todo.

La categoría lógica general de flujo (Flu $\beta)$ es determinada, en El capital de Marx, como flujo de entrada $(Z u f l u \beta)$, flujo de salida $(A b f l u \beta)$ y flujo de retorno (Rückfluß). Flujo (Fluß) se aplica tanto a los factores objetivos de la producción y circulación cuanto a los signos de valor que en esta operan.

Tratándose del flujo de retorno (Rückfluß) de la inversión, afirma Marx (1962):

[E]l flujo de retorno del dinero a su punto de partida no depende de si la mercancía se vende más cara de lo que se compró. Esto solo afecta la cantidad de la suma de dinero que fluye de vuelta. El fenómeno del flujo de retorno, en sí, ocurre tan pronto la mercancía comprada es revendida, es decir, tan pronto el ciclo D-M-D es completado. (p. 164)

Así, el flujo de retorno (Rückfluß) ocurre como un feedback, como un lazo de realimentación, resultando en un retorno idéntico, disminuido o ampliado de dinero para un nuevo flujo de reproducción del valor.

\section{(c) Determinación del valor económico}

Desde la economía de liberación, el valor económico puede ser determinado tanto como valor-capital o como valor-solidario a depender del circuito, modalidad y propósito de su producción, circulación y empleo.

Para Marx, el valor-capital (Kapitalwert) es lógicamente determinado, bajo aspectos diversos, como capital fijo (fixes Kapital), capital circulante (flüssiges Kapital), capital-dinero (Geldkapital) y capital-mercancía (Warenkapital).

Marx distingue el valor-capital (Kapitalwert) —en su forma más general— de sus formas específicas, determinadas en su pasaje (entrada, salida y retorno) por los ámbitos de la producción y de la circulación.

El capital productivo (produktives Kapital) integra en sí el capital-fijo (fixes Kapital) y 
capital-circulante (flüssiges Kapital). Su valor se transporta al producto que, en seguida, deviene mercancía en el proceso de su circulación.

Capital de circulación (Zirkulationskapital) integra en sí el capital-dinero (Geldkapital) y capital-mercancía (Warenkapital). En el intercambio, ellos pasan de manos en el mercado para la reproducción del capital.

\section{(d) Ciclos de producción y reproducción del capital}

Los flujos de producción y reproducción del capital ocurren en el tiempo de su metamorfosis, desde la inversión hasta la realización de la ganancia, que se puede denominar de ciclos.

En estos ciclos, el flujo del proceso de reproducción del capital puede ser acelerado, retardado o bloqueado. Por eso, como subraya Marx, siempre que condiciones reales, requeridas para la reproducción del valor, no estén adecuadamente presentes, «hay un estancamiento en la reproducción, así en el flujo de la circulación» (Marx, 1967, p. 495). Y cuando ese flujo, en alguna medida, se estanca, nuevos flujos de capital dinero devienen necesarios a los capitalistas: «ese flujo puede estancarse en mayor o menor medida, razón por la cual nuevas reservas monetarias se hacen necesarias del lado de los capitalistas» (Marx, 2015, p. 629).

En cada ciclo entran valores como inversión y en su final salen valores como resultado, que pueden ingresar otra vez como nueva inversión o no. Cuando salen del proceso de producción y circulación, entran en el atesoramiento, que puede ocurrir en los bancos, desde donde pueden salir otra vez para alimentar la producción, la circulación o el consumo.

Marx usa la expresión flujo de entrada $(\mathrm{Zuflu} \beta)$ y flujo de salida $(\mathrm{Abflu} \beta)$ con respecto, por ejemplo, a los fondos de reserva de los bancos: «En qué medida ese capital monetario queda ocioso, solo es revelado por los flujos de entrada y salida en los fondos de reserva de los bancos» (Marx, 1964, p. 517).

\section{(e) El valor-capital y el plus-valor}

Al formular la categoría de valor-capital (Kapitalwert), Marx supone una otra categoría lógica más general y sencilla, que es la categoría de valor (Wert).

Ejemplo: hablando de la inversión fijo total, con relación a cada ciclo de reproducción del valor, dice «que su valor circula de modo fraccionado» [daß sein Wert bruchweis zirkuliert] (Marx, 1963, p. 193).

Solamente en el plan lógico del valor (Wert), se puede formular la categoría lógica de plusvalor, plusvalía (Mehrwert), para identificar el valor nuevo, presente en el producto, que ha sido creado por el trabajo, frente al restante valor del producto, reproducido por el trabajo y que puede ser cuantificado considerando el valor total del capital invertido en su producción y traspasado al producto.

\section{(f) El fundamento del valor: capacidades y necesidades humanas}

Si el objeto de la investigación de Marx fuera el valor y no el capital, el análisis dialéctico no se quedaría en la contradicción en que el trabajo produce el capital.

El análisis avanzaría más un paso, llegando a la relación dialéctica entre capacidades y necesidades humanas, pues el valor, en su singularidad, se objetiva materialmente como valor 
de uso de algo que atiende a algún propósito humano, a alguna necesidad para la realización de alguna libertad.

Marx avanza a este nivel al analizar el intercambio que ocurriría en la fase superior del comunismo, considerando como el intercambio y la apropiación económica podrían transitar de la centralidad sobre los valores de cambio hacia la centralidad del justo encuentro entre las necesidades y capacidades de cada persona y de la comunidad en su todo, con base al principio que dice: «de cada cual según su capacidad; y a cada cual según su necesidad» (Marx, 1987, p. 21).

\section{(g) Circuitos económicos: del abstracto al concreto}

Los tres anillos del valor-capital están interconectados: capital productivo (produktives Kapital), capital comercial (kommerzielles Kapital) y capital crediticio (Kreditkapital).

Ellos están entrelazados en el flujo de valores en el sistema, porque el valor acumulado en cualquier uno de esos tres anillos en un sistema solvente se relaciona al valor de uso producido por el trabajo.

Eso nos da la comprensión formal, abstracta, de la producción, circulación y acumulación del capital. Pero solamente cuando analizamos cómo los circuitos del capital se integran con los circuitos no-capitalistas de producción del valor, tenemos la comprensión concreta de la producción y circulación del valor económico y como él se manifiesta en dos diferentes circuitos, como valor-capital y como valor-solidario.

El valor singular de uso del producto solamente se convierte en valor particular de cambio si el producto porta o posee un valor social de uso. Por otra parte, el dinero, como representación del valor universal de crédito en el seno de una formación social, solamente se convierte en capital cuando es invertido en el proceso del capital. El empleo de un signo de valor como medio para obtención de valores de uso solamente es posible por un acuerdo ejercitativo - voluntario o impuesto- entre miembros de una formación social que lo emplean de ese modo, relacionándolo a un valor universal de crédito.

Así, sea como valor singular de uso, sea como valor universal de crédito, productos y signos de valor tanto pueden ser determinados históricamente como valor-capital o como valor-solidario.

Toda determinación relaciona en sí tres aspectos: afirmación, negación y limitación.

Por eso, el valor producido bajo relaciones de producción capitalista puede, en el proceso de la circulación, ser históricamente realizado, afirmado, como capital, puede ser completamente negado en su realización como capital o parcialmente limitado, por esa negación, en su realización como capital.

Por otra parte, el mismo se pasa con el valor producido bajo relaciones de producción solidarias, que, en el proceso de su circulación, puede ser realizado, afirmado, como valor solidario, puede ser completamente negado como valor solidario o parcialmente limitado como valor solidario.

\section{(h) Los circuitos económicos del capital productivo, comercial y crediticio}

El circuito económico del capital, conectando producción, intercambio y crédito puede ser representado en la figura 1 (ver Figura 1). 


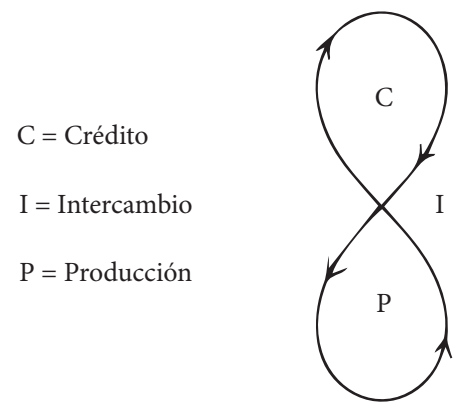

El proceso continuo de reproducción del valor puede ser representado como un flujo de valor que pasa por los anillos del Crédito y de la Producción, entrelazados por un lazo de realimentación que es el Intercambio, determinado como valor-capital por su forma de producción y de apropiación.

Ese lazo de intercambio da origen a anillos que le son propios para la circulación de medios económicos, valores económicos y representaciones de valores económicos —que no están representados en la figura-. Estos flujos se relacionan, igualmente, a procesos de consumo, integración con los ecosistemas, a relaciones políticas, culturales y sociales, todos ellos de carácter opresivo, que reniegan al buen vivir de todos/as.

De hecho, cuando analizamos el sistema socioeconómico actual, vemos que él destruye ecosistemas y sujeta las libertades privadas y públicas a diferentes formas de opresión.

En las relaciones de producción, hay la explotación del trabajador y de la naturaleza, generando una plusvalía que es el tiempo de trabajo no pago.

En las relaciones de intercambio, hay la realización de la plusvalía como ganancia y la expropiación del comprador cuando por el producto se pague más de lo que valga y de los costos de su circulación.

En las relaciones de crédito, existe la expoliación del deudor, que paga tasas de interés superiores a la cobertura de los costos de la propia operación de préstamo.

En las relaciones de consumo, existe la privación relativa de los consumidores, en grados variables, dependiendo del dinero que puedan ofrecer para satisfacer a sus necesidades.

En las relaciones de integración con los ecosistemas, existe la degradación ambiental, que impacta en el equilibrio dinámico de la tela de la vida en todo el planeta, contaminando los suelos, el aire, los ríos y océanos, llevando a la extinción de especies, al calentamiento del planeta, generando disturbios climáticos, etc., tratando todo lo que hay, seres vivos o inanimados, como medios para la obtención de ganancias y acumulación de capital.

En las relaciones políticas y culturales, en su integración a los flujos de poder y de conocimiento, existe la dominación y represión de las personas, que se ven obligadas a someterse a relaciones opresivas de subordinación.

En las relaciones sociales de su integración a la sociedad como un todo, existe la marginalización y la exclusión, en grados diversos, teniendo disminuido el acceso a los medios requeridos a la realización de su buen vivir. 


\subsection{CIRCUITO ECONÓMICO SOLIDARIO}

En el circuito económico solidario hay un proceso continuo de reproducción del valor-solidario, que puede ser representado como un flujo de valor pasando por los anillos del Crédito y de la Producción, entrelazados por el Intercambio como su lazo de realimentación (ver Figura 2).

El crédito solidario es representado en diferentes signos de valores monetarios y no-monetarios, monedas, vales, etc., aceptados en el seno de comunidades económicas solidarias.

La producción solidaria es realizada con el fin último de asegurar la libre apropiación de los medios económicos para el ejercicio de las libertades públicas y privadas de todos, de modo ético, mirando sostener y expandir el buen vivir personal y colectivo de todos/as.

El intercambio solidario, en la metodología propuesta, es realizado directamente entre los actores económicos o indirectamente por intermedio de los emporios de los circuitos - valiéndose o no de plataformas de economía solidaria-. Las modalidades de intercambio solidario integran comprar-y-vender, trocar y dar-y-recibir gratuitamente. Los productos y signos de valores intercambiados en esas modalidades cumplen su función social de atender a las necesidades de las personas y preservar el crédito en el seno de la comunidad.

\subsection{LA INTERSECCIÓN E INTERPENETRACIÓN DE FLUJOS DE VALOR} DE LOS CIRCUITOS ECONÓMICOS CAPITALISTA Y SOLIDARIO

\section{(a) Los flujos de valor en la reproducción del capital como totalidad concreta}

En sus esquemas de análisis de la reproducción del capital, Marx siempre principia por un valor adelantado que será utilizado en la producción y realización del valor. Como el valor generado al final es mayor que el valor invertido inicialmente, hay cómo pagar el valor adelantado y restar aún algún valor como ganancia al empresario. Pero, por otra parte, considerando el valor que el capital distribuye a cada ciclo de producción para consumo, no habría valor suficiente para asegurar la venta de la mercancía puesta en circulación en el ciclo sucesivo.

Esto abrió un amplio debate con dos posiciones diferentes acerca de cómo, concretamente, el capitalismo crece si no distribuye el suficiente para asegurar la propia venta de la totalidad de mercancías ofrecidas a cada ciclo de producción.

De su parte, Rosa Luxemburgo afirma que valores no producidos ni distribuidos en el circuito del capital ingresan en él como condición de la realización completa de la reproducción ampliada del valor-capital.

De hecho, al analizar los esquemas de reproducción del Libro II de El capital, ella percibe que no había una distribución suficiente de valor entre operarios y capitalistas para activar la compra total de la producción y, así, para realizar la plusvalía en la forma de ganancia y asegurar, de ese modo, la reproducción ampliada del capital. Por eso, Rosa destaca que «la realización de la plusvalía para fines de acumulación es una tarea imposible en una sociedad que consista solamente de trabajadores y capitalistas» (Luxemburg, 1975, p. 300). Para ella, «el punto decisivo es que la plusvalía no puede ser realizada por los trabajadores ni por los capitalistas, pero por camadas sociales o sociedades que no producen de modo capitalista» (Luxemburg, 1975, p. 300) y que compran los productos generados bajo el comando del capital. 


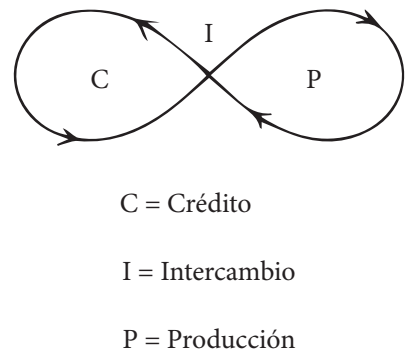

Muchos criticaran a Rosa porque, si así fuera, el capitalismo no tendría cómo expandirse por sí mismo, dependiendo de valores producidos en relaciones de producción no capitalistas.

La otra posición enfatizaba que los valores atesorados y el valor del patrimonio ya acumulado, dado en garantía de préstamos, entraban en circulación por intermedio del capital a crédito. Y que, el crédito, al mismo tiempo que ampliaba deudas, posibilitaba ampliar la producción. De este modo, si el volumen de valor producido era mayor que el volumen de la deuda contraída, el sistema podría crecer. Pero, por otra parte, como hay desequilibrios en esto, periódicamente tales deudas llevan a situaciones de insolvencias, con las tasas de interés sobrepasando las tasas de ganancia, comportándose el endeudamiento como elemento de crisis periódicas y de quiebras sistémicas, cuando entonces las deudas se esfuman y el sistema se relanza otra vez.

Pero, de hecho, las dos posiciones tienen elementos válidos para comprender la totalidad concreta del capital, para entender la unidad entre la identidad del valor-capital y la diferencia del valor-solidario en la reproducción ampliada misma del valor económico total.

La intersección de los circuitos económicos del capital y de los circuitos económicos solidarios es real y ocurre en los mercados locales. De hecho, el mercado mundial se compone de todos los mercados locales e interconecta sus flujos económicos.

\section{(b) La realidad de los flujos económicos}

Cuando analizamos los flujos de entrada, salida y circulación de valor económico en los dos circuitos en su totalidad concreta, vemos que ellos están interconectados (ver Figura 3).

Vemos que producto y dinero pueden migrar de un circuito a otro y realizarse como valorcapital o valor-solidario.

Así, valores de uso, producidos en la economía solidaría o en la economía del capital, pueden ser cambiados por signos de valor tanto en el circuito del capital cuanto en el circuito solidario. Y signos de valor, que operan como crédito en la economía solidaría o en la economía del capital, pueden realimentar la producción tanto en el circuito económico solidario cuanto en el circuito económico del capital.

(c) La posibilidad de liberación de los flujos económicos

Productos y dineros pueden salir del circuito económico del capital e ingresar en el circuito 
económico solidario y cumplir un papel diverso en la producción y circulación del valor económico, incluso antagónico a la propia reproducción del capital.

Así, valores generados en los circuitos económicos del capital pueden ser realizados como excedentes de valor en los circuitos económicos solidarios y ser vertidos a fondos de crédito solidario para liberación económica de los trabajadores, consumidores y de sus comunidades.

Y, con esto, mientras los sectores de producción, intercambio y crédito de la economía solidaría se expanden, los sectores de producción, intercambio y crédito de la economía capitalista tienden a debilitarse y, por fin, a desaparecer, pues ellos no pueden sobrevivir sin la reproducción ampliada del valor que los alimenta y que requiere la venta de sus mercancías como momento de realización del valor.

\subsection{COMO EL VALOR-SOLIDARIO SE CONVIERTE EN VALOR-CAPITAL}

EN PROCESOS DE DOMINACIÓN ECONÓMICA

Sin embargo, valores producidos en la economía solidaria, autogestionada, son acumulados en la reproducción ampliada del capital en los circuitos económicos del capital, por vía del mercado mundial de varios modos.

1. Cuando productos generados en los circuitos solidarios son comercializados en los circuitos del capital con la realización de ganancias por el capital mercantil (comercial y financiero). 2. En operaciones de financiación de producción y comercialización solidarias, con el pago de interés a bancos privados que proveen crédito.

3. Con la adquisición de productos finales o medios productivos, por actores de la economía solidaría, de proveedores capitalistas, siempre que haya expropiación en estos intercambios, con términos de cambio desfavorables a los actores solidarios.

4. Con la contratación de iniciativas solidarias para trabajar para iniciativas capitalistas con remuneración injusta del trabajo o no cobertura de otros costes.

\subsection{COMO EL VALOR-CAPITAL SE CONVIERTE EN VALOR-SOLIDARIO}

EN PROCESOS DE LIBERACIÓN ECONÓMICA

Marx ha empleado la categoría de liberación (Befreiung) y sus variantes más de 400 veces en sus escritos. Entre otros empleos, abordó la liberación del valor-capital y del trabajo con respecto a su aplicación en la producción y reproducción del valor económico, bien como con respecto a su pasaje de un sistema económico a otro.

\section{(a) En el proceso de la reproducción ampliada del valor}

En el proceso de su reproducción ampliada, ocurre la liberación del capital que, al metamorfosearse de la forma producto en mercancía y de esta en la forma dinero, posibilita un nuevo ciclo (rotación o giro) de reproducción ampliada del valor por una nueva inversión. El capital libertado en la forma dinero, se convierte otra vez en factores productivos, pudiendo ese lazo de reproducción ampliada expandir, de manera geométrica, la fuerza productiva existente.

Así, cuando la mercancía es vendida realizando la ganancia, el capital invertido en su producción y circulación y la plusvalía en ella existente se libertan de esa forma singular y concreta de valor y asumen la forma universal de riqueza en el valor de cambio del dinero. 


$$
\begin{aligned}
& \mathrm{CS}=\text { Crédito solidario } \\
& \mathrm{CC}=\text { Crédito capitalista } \\
& \mathrm{PS}=\text { Producción solidaria } \\
& \mathrm{PC}=\text { Producción capitalista } \\
& \mathrm{I}=\text { Intercambio }
\end{aligned}
$$

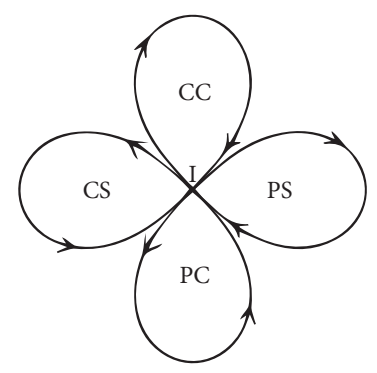

(b) En el proceso de transición de un sistema a otro

El valor puede ser libertado de un modo de producción anterior para un modo de producción posterior - como ocurrió entre el feudalismo y el capitalismo- Como estos modos de producción coexisten durante un cierto período, se trata del paso del trabajo y del capital de un modo a otro de producción que, en el caso analizado por Marx, preserva la misma forma de trabajo subordinado y de capital subordinante, pues este es producido con la explotación de aquello:

[...] el necesario desarrollo del trabajo es la industria liberada y constituida para sí misma como tal, y el capital liberado. [...] Con la transformación del esclavo en trabajador libre, esto es, en un asalariado, el señor de la tierra en sí se transformó en señor de industria, en capitalista [...]. Pero [...] el capitalista sabe el propietario de tierras como [...] el señor [...] de ayer, [...] ve en él una oposición a la industria libre y al capital libre, independientemente de toda determinación natural. (Marx, 1968, p. 526)

Marx destaca la necesidad de la clase obrera realizar la liberación de las fuerzas productivas para la superación del capitalismo. Las fuerzas productivas se liberarían en la medida en que el trabajo no estuviera más subordinado al capital y los trabajadores se apropiasen de los medios de producción, para continuar su desarrollo tratando de atender a las necesidades de todos:

$\mathrm{Al}$ crear los inagotables poderes productivos de la industria moderna, ellos [los trabajadores] cumplieron la primera condición de la emancipación del trabajo. Ellos ahora tienen que percibir su otra condición. Ellos tienen que liberar los poderes productivos de riquezas de los infames grilletes del monopolio y someterlos al control conjunto de los productores, quienes, hasta ahora, permitieron que los mismos productos de sus manos se volvieran contra ellos propios y se transformaran en otros tantos instrumentos de su propia subyugación. (Marx, 1953, p. 215, corchete nuestro)

En la economía de liberación, analizamos cómo el valor económico puede ser negado como valor-capital para ser determinado como valor-solidario en un sistema económico poscapitalista.

Considerando los momentos de su metamorfosis, en que el capital asume la forma general de valor (Wert) — como signo de valor o producto-, podemos concluir que, a depender del circuito en el cual ese valor es invertido o usado y del propósito con el cual tal inversión o 
empleo ocurren, él puede realizarse o no como valor-capital (Kapitalwert) o como valor-solidario (Solidarwert).

Si no fuera así, jamás podría ocurrir la liberación de las fuerzas productivas, de intercambio y de crédito y la sociedad capitalista sería eterna.

Es posible la libertación ${ }^{1}$ del valor económico en el flujo de su salida (Abfluß) del sistema económico vigente, capitalista, para su ingreso $(Z u f l u \beta)$ en el proceso de constitución de un nuevo sistema económico, activando los lazos de reproducción ampliada (Rückfluß) del valor-solidario.

\section{CIRCUITO ECONÓMICO SOLIDARIO Y BUEN VIVIR}

\subsection{TRAYECTORIA INICIAL DE LOS CONCEPTOS (1999 A 2008)}

En nuestro libro La revolución de las redes (Mance, 1999), analizamos los «flujos de realimentación interna de valor» (p. 129) en los circuitos económicos de una red solidaria en su relación con el flujo de valor del mercado capitalista: «Cuanto más grande el grado de realimentación interna de la red [...], mayor facilidad ésta tendrá para ajustar la composición orgánica de cada célula a la estrategia autopoiética de su expansión» (p. 132). Subrayamos que «formalizando los vectores de los flujos de valor, podemos ecuacionar, entre otros aspectos, el punto y el margen de equilibrio de una red particular, su grado de retroalimentación y su tasa de expansión» (p. 140), considerando los flujos de salida de valor (Abfluß), de ingreso de valor $(\mathrm{Zuflu \beta})$ y de realimentación del valor (Rückfluß). En este libro, lo hicimos considerando las células de producción, circulación y consumo y las resultantes de su interconexión en red. La figura 4 muestra la formalización de flujos de valor en una célula productiva, mapeados en entradas (h, i) circulación interna (e,f, g) y salidas (j, k, l, m), que no hay cómo detallar acá (ver Figura 4).

En los flujos de realimentación interna de las redes, se puede generar créditos - como signos de valor- que se compensan en el intercambio material de bienes y servicios, que, a través de una plataforma de economía solidaria, puede ser integrado en niveles local y global:

Como todas las células estarán conectadas en una red informatizada [...], gran parte de la economía de la red no envolverá monedas corrientes en las acciones de consumo productivo o final. Actualmente [1999] el comercio por Internet ya provocó la digitalización de las monedas que son utilizadas en las transacciones comerciales [...]. Es perfectamente posible, con la tecnología ya disponible, efectuar transacciones de compra y venta de productos entre las células de la red utilizando créditos [electrónicos] [...]. Lo interesante es que la unidad de estos créditos se convierta en un nuevo patrón monetario mundial [...] que no está sujeto a la especulación, a la inflación y que se mantiene estable incluso con la reducción progresiva de la jornada laboral de todos. [...] Es decir, los créditos circularán como una moneda digital universal [...]. (Mance, 1999, pp. 161-162, corchete nuestro)

La figura central del circuito es el lazo de realimentación interna (Rückfluß) del valor, que permite su reproducción ampliada y la expansión de las capacidades de liberación de las fuerzas de producción, intercambio y crédito en los circuitos solidarios. 


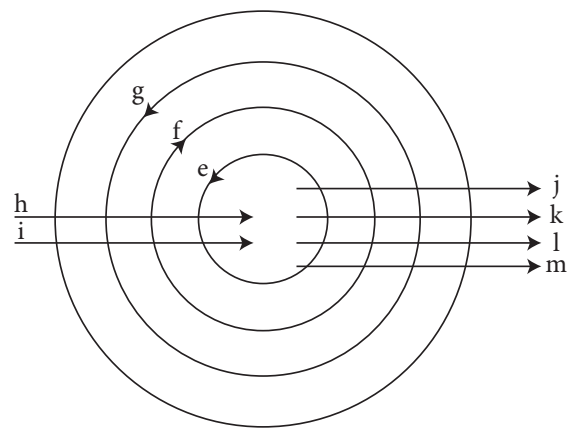

Con esta lógica, el Núcleo de Economía Solidaria del Instituto de Filosofía de la Liberación avanzó en la organización de una plataforma, inicialmente llamada redesolidaria y después solidarius.net, para apoyar la multiplicación de circuitos económicos integrando «consumo, comercio, producción y crédito solidarios», en la forma de redes de colaboración solidaria. En la portada de la plataforma, se afirmaba:

[C]uando [...] practicas el consumo solidario, además de asegurar tu buen vivir, contribuyes para suprimir la explotación de los trabajadores y a mantener el equilibrio de los ecosistemas. La práctica del consumo, comercio, producción y crédito solidarios es capaz de hacer posible la construcción de una nueva sociedad más justa y ecológicamente equilibrada [...], constituyendo una alternativa viable para asegurar el buen vivir de todas las sociedades. (Mance, 1999b, p. 1)

En Redes de colaboración solidaria (Mance, 2002), con respecto a la realimentación interna (Rückfluß), se profundiza que:

[U]n lazo de retroalimentación positiva [...] puede entenderse como un tipo matemático de proceso no lineal llamado iteración en el que una función opera repetidamente sobre sí misma.

En efecto, los lazos de retroalimentación positiva en una red económica de producción y consumo permiten que los excedentes obtenidos - que se considerarían ganancia bajo la lógica capitalista - se vuelvan a aplicar en el proceso de producción y en el soporte social del consumo, de manera que los valores producidos por el trabajo se multipliquen constantemente bajo patrones de autoorganización, ecológica y socialmente sostenibles. (pp. 64-65)

Los cúmulos de estas investigaciones y acciones generaron publicaciones sobre cómo organizar redes y circuitos de economía solidaria, que fueron parcialmente incorporados en el Programa Hambre Cero, en Brasil, en el primer Gobierno Lula.

En Cómo organizar redes solidarias (Mance, 2003), se subraya que, una vez comprendido cómo los flujos transitan por los circuitos, se trata de reorganizarlos, pues el valor puede salir o realimentar el circuito solidario:

[...] el valor económico producido en cada etapa de la cadena de producción circula a través de la red, pudiendo concentrarse en ella o escapar de ella. Es decir, cuando una célula productiva 
compra insumos del mercado capitalista [...], una cierta cantidad de valor sale de la red realimentando el giro capitalista. Sin embargo, si una nueva célula que produce ese insumo se crea en conexión con las otras [...], entonces ese valor [...] sigue alimentando la producción de otra célula de la red. Por otra parte, si lo que se produce en la red es consumido por grandes parcelas de la sociedad [...], entonces el volumen de valor que resulta de este proceso se concentra en la realimentación de la red. El excedente de valor producido por la red puede utilizarse para crear nuevas unidades de producción que satisfagan las demandas de producción o consumo final de la propia red [...]. (p. 302)

En el libro Hambre cero y economía solidaria (Mance, 2004), se propone esta estrategia. Como se ve, en la metodología de implantación de las acciones estructurales de este programa por el Gobierno de Brasil:

«[...] se articulan dos grandes bloques de acciones, para construir y fortalecer el circuito económico solidario y para la consolidación estratégica de los emprendimientos económicos solidarios en la economía formal [...]». (p. 94)

En el detalle de estas acciones:

[S]e visualiza que el proceso de construcción y fortalecimiento del circuito económico solidario implica [...] el mapeo y diagnóstico de las cadenas productivas de la región [...], lo que permitirá implementar la producción bajo demanda y reorganizar estas mismas cadenas productivas para que los flujos económicos a través de estos territorios potencialicen su propio desarrollo sostenible, integrando finanzas, producción, comercialización y consumo solidarios en una estrategia de redes de economía solidaria. (Mance, 2004, p. 95)

Facilitando la integración del consumo y de la producción de los territorios entre sí, se organizan centrales de comercialización:

[E]n la medida en que las centrales con sede en distintos municipios están interconectadas en redes, es posible asegurar el traslado de productos de economía solidaria entre distintas regiones, facilitando su comercialización, ampliando la oferta en diversidad para los consumidores y asegurando la expansión del circuito económico solidario. (Mance, 2004, pp. 128-129)

También se plantean acciones de finanzas solidarias y organización de fondos «[...] permitiendo diversas operaciones de crédito que refuerzan los circuitos económicos solidarios, basados en el ahorro interno» (Mance, 2004, p. 176).

A su vez, en Constelacíón solidarius (Mance, 2008):

[L]a búsqueda de la convergencia de las tecnologías sociales y su interoperabilidad [...] se llevó a cabo con el fin de [...] explotar [...] las grietas sistémicas del capitalismo [...] [para] desviar los flujos de valores que lo realimentan para realimentar los circuitos de la economía solidaria, con el fin de hacer viable su expansión sostenible, posibilitando el surgimiento de sociedades pos-capitalistas, de un nuevo sistema que comparta los medios económicos para la expansión de las libertades públicas y privadas ejercidas éticamente, para la promoción del buen vivir de todas las personas y de la paz entre los pueblos. (p. 11)

$[\ldots]$ 
Se trata de un proceso que, al drenar los flujos de valores económicos para el circuito de la economía solidaria, realimente la expansión cada vez más fuerte de esta nueva economía, en la misma medida en que debilita el sistema hegemónico actual. (pp. 70-71)

\subsection{CÓMO CAMBIAR EL ÁMBITO DE REALIZACIÓN DEL VALOR ECONÓMICO}

DE LOS CIRCUITOS CAPITALISTAS PARA LOS CIRCUITOS SOLIDARIOS

Para cambiar el ámbito de realización del valor, de modo que se pueda drenar valores de los circuitos económicos del capital para generar fondos de liberación económica, se organizan circuitos económicos solidarios, gestionados por comunidades económicas, que pueden asumir la figura jurídica de cooperativas para autogestión comunitaria u otras figuras que sean las más adecuadas, según la legislación de cada país.

Para suplantar el modo de producción capitalista, la economía solidaria necesita primeramente liberarse del sistema de intercambio capitalista, pues, sin esto, la mayor parte del valor económico que ella produzca seguirá siendo acumulado por actores del capital en los circuitos económicos capitalistas, cuando en ellos se atiende al consumo de los hogares, de los emprendimientos y de los gobiernos.

Cuando analizamos los flujos de producción, circulación y acumulación de valores a nivel nacional, vemos que es el consumo de hogares lo que sustenta, en gran medida, la producción económica de un país.

Esta producción se divide entre dos sectores: el sector 1, que produce medios de producción, y el sector 2, que produce medios de consumo. El sector 2 compra medios productivos del sector 1 para producir medios de consumo. A su vez, las familias/hogares compran medios de consumo del sector 2, sosteniendo tanto la producción de medios de consumo, directamente, como de medios de producción, indirectamente.

Si las familias compran en los circuitos del capital, fortalecen al capitalismo. Si compran en los circuitos solidarios, fortalecen a la economía solidaria. Por eso, se parte del consumo de las familias para potenciar a ambos sectores ( 1 y 2) de la economía, en un proyecto de desarrollo que articula inversión y producción con el consumo sustentado de lo que es producido.

Así, [1] se parte del consumo de los hogares, para atender a las necesidades de consumo de las personas; [2] se organiza la adquisición de los medios de consumo demandados en emporios solidarios; [3] márgenes de excedentes obtenidos en el emporio, en la atención de este consumo, alimentan a fondos de liberación económica; [4] estos fondos realizan actividades de crédito solidario, autogestionadas por la comunidad, para liberación de fuerzas de producción y circulación; [5] se organiza, de manera solidaria y ecológica, la producción y circulación para abasto de los emporios con inversión de los valores de los fondos.

Y como todo emprendimiento integrado al circuito solidario igualmente necesita consumir medios de producción y de circulación, entonces: [6] el consumo de los emprendimientos solidarios de producción y de circulación es dirigido a los emporios solidarios; [7] se organiza la adquisición de los medios de producción y de circulación en los emporios solidarios para atender a las necesidades de los emprendimientos de producción y circulación; [8] márgenes de excedentes obtenidos en el emporio en la atención de este consumo igualmente alimentan a los fondos de liberación económica. 
Para facilitar la integración de los flujos económicos de producción, circulación, consumo y crédito de cada circuito y la interconexión entre todos ellos [9] se organizan plataformas de economía solidaria, posibilitando acciones conjuntas a niveles local, regional, nacional y global.

Veamos una proyección como ejemplo.

Con base en datos de 2018, Colombia registró usD 330 mil millones en su producto interno bruto. El consumo de hogares en el país en aquel año fue $68 \%$ del PIB, lo que correspondió a USD 224 mil millones. Al cierre de 2017, había 6.386.170 asociados a cooperativas en Colombia, con núcleos familiares que alcanzaban a 19 millones de personas (39\% de la población). Por hipótesis, imaginemos que algo como $39 \%$ del consumo de hogares fuera practicado por familias de cooperativistas. Eso significa que aproximadamente USD 152 miles de millones serían consumidos por año por familias cooperativistas en Colombia.

Así, los circuitos económicos solidarios en Colombia podrían, en esta proyección, facturar USD 152 miles de millones por año, solamente para atender al consumo de las familias de cooperativistas. Si 10\% de esta facturación fuera destinada a fondos de liberación económica, esto resultaría en USD 15,2 miles de millones por año para inversiones en plantas de producción y circulación, activando las cadenas productivas del sector 2 y, por consecuencia, del sector 1 de la economía nacional.

Si las 6.386.170 familias de cooperativistas de Colombia se organizaran en circuitos económicos solidarios, haciendo las compras mensuales para su hogar en emporios de economía solidaria que estén interconectados nacionalmente en una plataforma de economía solidaria, esto resultaría en un ingreso anual próximo de USD 100 mil millones. Si 10\% de estos ingresos se realizaran como excedentes y fueran canalizados a fondos de liberación económica, tendríamos USD 10 mil millones para inversiones anuales en distintas cadenas de producción y circulación, creando empresas cooperativas en los sectores 1 y 2 para sustituir medios de producción y medios de consumo que los emporios solidarios aún compren de los circuitos económicos del capital.

Estos fondos, por la metodología propuesta en la economía de liberación, son autogestionados por los trabajadores, consumidores y sus comunidades y destinados al desarrollo tecnológico, compra de máquinas, herramientas e instalación de nuevas plantas productivas y de intercambio, buscando reorganizar las cadenas del sector económico solidario, orientadas a que sean ecológicamente sustentables y socialmente justas.

Así, valores que antes eran realizados como ganancias del capital comercial y financiero, se realizan ahora como excedentes de valores económicos que alimentan fondos de liberación económica para el buen vivir de todos/as. Y como se expanden la producción, circulación y el consumo solidarios, las empresas capitalistas del sector de producción realizan menos valor como ganancias al paso que las iniciativas productivas de la economía solidaria realizan volúmenes mayores de valor que se destinan a los fondos de liberación económica, pues tales iniciativas son autogestionadas por sus trabajadores y sus comunidades económicas.

\section{NOTA}

1 La diferencia entre liberación y libertación reside en el ejercicio de la autonomía y de la autodeterminación de la praxis por parte de los actores que se liberan o en su ausencia por parte de las cosas o 
personas que son libertadas. La liberación ocurre cuando las personas son sujetos históricos del proceso de expansión de sus libertades. La libertación se da cuando algo o alguien es removido de una función o condición específica por terceros, haciendo posible ser empleado en otra función o colocado en otra condición. Así, las fuerzas productivas, de intercambio y de crédito y las comunidades humanas, por ser actores históricos, se liberan; al mismo tiempo que los medios de cambio (productos y signos de valor) o medios de trabajo son libertados.

\section{REFERENCIAS}

Luxemburg, R. (1975) Die Akkumulation des Kapitals - Ein Beitrag zur ökonomischen Erklärung des Imperialismus. In Gesammelte Werke. Herausgegeben vom Institut für Marxismus-Leninismus beim zK der SED. Band 5: Berlin, pp. 5-411.

Mance, E. A. (1999). A revolução das redes. Petrópolis: Vozes.

Mance, E. A. (1999b). Todos somos responsáveis pelo bem viver de todos! Curitiba: IFil. Disponible en http:// web.archive.org/web/20010330214355/http://www.redesolidaria.com.br/ [Acceso en 26/o9/2020]

Mance, E. A. (2002). Redes de colaboração solidária. Petrópolis: Vozes.

Mance, E. A. (2003). Como organizar redes solidárias. IFiL, Fase, DP\&A.

Mance, E. A. (2004). Fome Zero e economia solidária. Curitiba: IFiL, Editora Gráfica Popular.

Mance, E. A. (2008). Constelação solidarius - As fendas do capitalismo e sua superação sistêmica. Passo Fundo, Ifibe.

Mance, E. A. (2017) Circuiti economici solidali. Economia solidale di liberazione. Roma: Pioda.

Marx, K. (1953). Letter to the Labour Parliament. In: Marx Engels on Britain. Moscou: Progress Publishers.

Marx, K. (1956). The metamorphoses of capital and their circuits. In: Capital - volume II. Moscou: Progress Publishers.

Marx, K. (1962). Verwandlung von Geld in Kapital. In: Karl Marx/Friedrich Engels - Werke. Dietz Editora., Berlim. Volume 23, pp. 161-191.

Marx, K. (1963). Theorien über fixes und zirkulierendes Kapital - Die Physiokraten und Adam Smith. In :Karl Marx/Friedrich Engels - Werke. Dietz Verlag, Berlim. Volume 24, pp. I89-2I6.

Marx, K. (1964). Geldkapital und wirkliches Kapital. In: Karl Marx/Friedrich Engels - Werke. Dietz Verlag, Berlim. Volume 25, pp. 5II-520.

Marx, K. (1967). Ricardos Akkumulationstheorie - Kritik derselben (Entwicklung der Krisen aus der Grundform des Kapitals). In: Karl Marx/Friedrich Engels - Werke. Dietz Verlag, Berlim. Band 26, Zweiter Teil, pp. 471-547.

Marx, K. (1968). Ökonomisch-philosophische Manuskripte. In: Karl Marx/Friedrich Engels - Werke. Dietz Verlag, Berlim. Volume 40, pp. 465-588.

Marx, K. (1987). Randglossen zum Programm der deutschen Arbeiterpartei. In: Karl Marx/Friedrich Engels - Werke. Dietz Editora, Berlim. Volume 19, pp. 15-32.

Marx, K. (2015). O Capital - Livro II . Crítica da economia política - O Processo de circulação do capital. São Paulo: Boitempo Editorial. 